\title{
Optimization of Extraction of Galangin from Galangal by Response Surface Method
}

\author{
Min Zheng ${ }^{1,2, a}$, Zheng Peng ${ }^{1}$, Jihua $\mathrm{Li}^{1}$, Lijing Lin ${ }^{1}$, Shaodan Peng ${ }^{1}$, Xiaobing \\ Huang ${ }^{1}$
}

${ }^{1}$ Agricultural Products Processing Research Institute, Chinese Academy of Tropical Agricultural Sciences, Zhanjiang 524000, China;

${ }^{2}$ School of Food Science and Technology, Huazhong agricultural University, Wuhan 430000, China.

azhengmin013@163.com, bHuang5012@hotmail.com

Corresponding Author: Xiaobing Huang

Keywords: Galangin,Extraction,Response Surface Method.

Abstract. Based on the single-factor experiments of galangin extraction from the galangal,the experimental variables, the ethanol concentration $\left(\mathrm{X}_{1}\right)$, extraction temperature $\left(\mathrm{X}_{2}\right)$, extraction time $\left(X_{3}\right)$, and ratio of thanol to raw materia $\left(X_{4}\right)$ were estimated and optimized by the response surface methodology (RSM). The statistical analysis indicated that the independent variables $\mathrm{X}_{2}$ and $\mathrm{X}_{4}$ had high significant effects on the response values,so are the interaction effects between the variables of $\mathrm{X}_{1} \mathrm{X}_{2}, \mathrm{X}_{1} \mathrm{X}_{4}, \mathrm{X}_{2} \mathrm{X}_{3}, \mathrm{X}_{2} \mathrm{X}_{4}$; the optimum extraction conditions for galangin were ethanol concentration $90 \%$, extraction temperature $80^{\circ} \mathrm{C}$, extraction time $3 \mathrm{~h}$, and the ratio of ethanol to materia $25 \mathrm{ml} \cdot \mathrm{g}^{-1}$.

\section{Introduction}

Galangal is the dry roots of Galangal plants,which belongs to Zingiberaceae ,Alpinia, it's located in Guangdong, Guangxi, Hainan, Yunnan, Fujian, Taiwan and other places. Galangal has a long history of cultivation, it's kind of famous specialty of Xuwen County in Guangdong Province, it sells good in home and abroad because of its unique medicinal value and health function. Galangal is hot in attribute,spicy in taste.It has function such as warm stomach, expelling wind, and dispelling cold, line gas, digestion and relieve pain ${ }^{[1]}$. Modern pharmacological research also shows galangal has pharmacological effects,for antibacterial, anti-viral, anti-oxidation, anti-tumor, anti-gastrointestinal bleeding, etc ${ }^{[2]}$.Its chemical composition is complex.as far,dozens of compound has been found in the medicinal material, mainly includes flavonoids, volatile oil and diaryl heptane compound ${ }^{[3]}$. Galangin (3,5,7-trihydroxy flavone) is one of the exclusive composition in galangal,it's also the active ingredient to reflect main function of galanga ${ }^{[4]}$.

Galangin is kind of natural flavonols, mainly extracted from the roots of galangal.Galangin has a significant effect in terms of chemical protection ${ }^{[5]}$, such as anti-oxidation, anti-ulcer,analgesic, antiemetic $^{[4,6,7]}$, anti-bacterial anti-inflammatory, inhibiting in vitro bowel movements ${ }^{[3]}$, and so on,in the process of vitiligo treatment with Galangin, Galangin is one of the active substances,Shixia $\mathrm{Huo}^{[8,9]}$ et al have proved this point in the efficacy experiment of galangin.Further studies have confirmed, galangin also has the function to anticancer ${ }^{[10,11]}$, induce apoptosis in cancer cells ${ }^{[12,13]}$,etc.Currently,reports about extraction galangin method is relatively few,so it is necessary to find an economical and high efficient method to extract galangin from the galangal.

Response surface methodology(RSM) is an affective statistical method to solve the problem of multivariable,it's simple, intuitive, less laborious and time-consuming,so it is widely used in optimizing the extraction process variables.

In this study, the main objective was to optimize the extraction process of galangin from galangal.RSM was designed to systemic analyze the effect of extraction parameters on the yields of 
galangin from galangal and their interactions .And it may provide theoretical reference for the technology extraction of galangin.

\section{Materials and Methods}

\subsection{Experimental Materials and Chemicals}

Galangal was purchased in wholesale market of Xuwen County in Guangdong Province,China.All chemicals used in this investigation were analytical grade and purchased from Guangdong Guanghua Science and Technology Co., Ltd. Instruments were purchased from SHIMADZU, Japan.

\subsection{Extraction and Determination Yield of Galangin from Galangal}

$10 \mathrm{~g}$ galangal rough powder was putted in $500 \mathrm{ml}$ round-bottomed flask,then added ethanol,reflux condensation in a water bath.The extract was suctioned by a vacuum pump, measured and record the volume $(\mathrm{V} / \mathrm{ml})$ of filtrate. $50 \mathrm{ml}$ filtrate was placed in the $500 \mathrm{ml}$ round-bottomed flask,rotary evaporation was adopted under the conditions of $60{ }^{\circ} \mathrm{C}$, until no further distilled droplets.Less than $50 \mathrm{ml}$ of methanol $(\geq 99.5 \%)$ were added to dissolve solids in the round-bottomed flask, galangin was extracted by the ultrasonic treatment, then set the volume to $50 \mathrm{ml}$ by methanol,shook the extract well and took a small part of it to the centrifuge tube and saved.

Since a certain concentration gradient of galangin standard solution was prepared, the sample's galangin $(\mathrm{C} / \mu \mathrm{g} / \mathrm{ml})$ was determined by HPLC (Chromatographic conditions: DAD detector, $\mathrm{C}_{18}$ column $(250 \times 4.6 \mathrm{~mm})$, column temperature: $40^{\circ} \mathrm{C}$, Mobile phase: methanol - water $(85: 15)$, flow rate: $1 \mathrm{ml} / \mathrm{min}$, detection wavelength: $266 \mathrm{~nm}$, sample volume: $10 \mu \mathrm{l})$. The galangin content was calculated by the following liner equation based on the calibration curve:

$\mathrm{A}=32350.9 \mathrm{C}-35839.1 \quad \mathrm{R}^{2}=0.9994$

Where $\mathrm{A}$ is the absorbance, $\mathrm{C}$ is the galangin content in $\mu \mathrm{g} / \mathrm{ml}$.

The percentage galangin yield $(\%)$ of the sample is calculated as follows:

Yield $=\mathrm{C} \times 50 \times 50 \times(\mathrm{V} / 50) / 10 / 1000000 \times 100 \%$

\subsection{The Response Surface Experimental Design}

Based on the single factor tests, a three level, four variable Box-Behnken factorial design (BBD)was applied to determine the best combination of extraction variables for the yields of galangin.Four extraction variables for this research were $\mathrm{X}_{1}$ (ethanol concentration), $\mathrm{X}_{2}$ (extraction temperature),, $\mathrm{X}_{3}$ (extraction time) and $\mathrm{X}_{4}$ (ratio of $60 \%$ ethanol to raw material), and $-1,0,+1$ represent the independent variable's low,medium and high levels respectively. Factors' coding and level can be seen in Table 1, 29 group tests were performed at all design points in randomized order, the design and the results shown in Table 2.

\subsection{Statistical Analyses}

Data were expressed as average of three replicated determinations. The responses obtained from each set of experimental design (Table 2) were subjected to multiple non-linear regressions using the Design Expert software. The quality of the fit of the polynomial model equation was expressed by the coefficient of determination $\mathrm{R}^{2}$, and the significances of the regression coefficient were checked by F-test and p-value.

Table 1 Level and code of independent variable for response surface analysis

\begin{tabular}{llll}
\hline lever & -1 & 0 & 1 \\
\hline $\mathrm{X}_{1}:$ ethanol concentration/\% & 60 & 80 & 100 \\
$\mathrm{X}_{2}:$ extraction temperature $/{ }^{\circ} \mathrm{C}$ & 60 & 70 & 80 \\
$\mathrm{X}_{3}:$ extraction time $/ \mathrm{h}$ & 3 & 3.5 & 4 \\
$\mathrm{X}_{4}:$ ratio of ethanol to materia/ml $\cdot \mathrm{g}^{-1}$ & 15 & 20 & 25 \\
\hline
\end{tabular}


Table 2 Box-Behnken experimental design with the independent variables.

\begin{tabular}{|c|c|c|c|c|c|c|}
\hline \multirow[t]{2}{*}{ Run } & \multicolumn{4}{|c|}{ Coded variable levels } & \multicolumn{2}{|c|}{ Yield of galangin (\%) } \\
\hline & $\overline{X_{1}}$ & $\mathrm{X}_{2}$ & $\mathrm{X}_{3}$ & $\mathrm{X}_{4}$ & Actual values & Predicted values \\
\hline 1 & -1 & 1 & 0 & 0 & 1.34 & 1.34 \\
\hline 2 & 0 & -1 & 0 & -1 & 1.41 & 1.43 \\
\hline 3 & 0 & 0 & 1 & 1 & 1.39 & 1.39 \\
\hline 4 & 1 & 0 & 0 & 1 & 1.32 & 1.33 \\
\hline 5 & -1 & 0 & 0 & 1 & 1.41 & 1.4 \\
\hline 6 & 0 & 0 & 0 & 0 & 1.34 & 1.36 \\
\hline 7 & -1 & 0 & -1 & 0 & 1.33 & 1.34 \\
\hline 8 & -1 & 0 & 1 & 0 & 1.37 & 1.38 \\
\hline 9 & 0 & 1 & 1 & 0 & 1.36 & 1.36 \\
\hline 10 & 0 & 1 & 0 & 1 & 1.57 & 1.58 \\
\hline 11 & 1 & 0 & 0 & -1 & 1.28 & 1.29 \\
\hline 12 & 0 & 0 & 0 & 0 & 1.34 & 1.36 \\
\hline 13 & 0 & -1 & 0 & 1 & 1.21 & 1.21 \\
\hline 14 & 0 & 0 & 1 & -1 & 1.33 & 1.31 \\
\hline 15 & 0 & 1 & 0 & -1 & 1.15 & 1.17 \\
\hline 16 & 0 & 1 & -1 & 0 & 1.48 & 1.47 \\
\hline 17 & 0 & 0 & -1 & 1 & 1.39 & 1.39 \\
\hline 18 & -1 & 0 & 0 & -1 & 1.26 & 1.25 \\
\hline 19 & 1 & 0 & 1 & 0 & 1.34 & 1.35 \\
\hline 20 & 0 & 0 & 0 & 0 & 1.38 & 1.36 \\
\hline 21 & 0 & -1 & -1 & 0 & 1.28 & 1.28 \\
\hline 22 & 0 & 0 & 0 & 0 & 1.39 & 1.36 \\
\hline 23 & 0 & -1 & 1 & 0 & 1.42 & 1.43 \\
\hline 24 & 1 & 0 & -1 & 0 & 1.32 & 1.34 \\
\hline 25 & 0 & 0 & 0 & 0 & 1.34 & 1.36 \\
\hline 26 & -1 & -1 & 0 & 0 & 1.39 & 1.39 \\
\hline 27 & 1 & -1 & 0 & 0 & 1.29 & 1.27 \\
\hline 28 & 1 & 1 & 0 & 0 & 1.45 & 1.43 \\
\hline 29 & 0 & 0 & -1 & -1 & 1.29 & 1.27 \\
\hline
\end{tabular}

\section{Results and Discussion}

\subsection{Regression Model and Significance Test}

A regression analysis (Table 2) was carried out by Design-Expert software. The predicted response $\mathrm{Y}$ for the yield of galangin could be expressed by the following secondorder polynomial equation in terms of actual values: $Y=3.21-4.734 \times 10^{-3} \mathrm{X}_{1}-0.055 \mathrm{X}_{2}+0.785 \mathrm{X}_{3}-0.132 \mathrm{X}_{4}+2.564 \times 10^{-4} \mathrm{X}_{1}$ $\mathrm{X}_{2}-5.475 \times 10^{-4} \mathrm{X}_{1} \mathrm{X}_{3}-2.633 \times 10^{-4} \mathrm{X}_{1} \mathrm{X}_{4}-0.013 \mathrm{X}_{2} \mathrm{X}_{3}+3.12 \times 10^{-3} \mathrm{X}_{2} \mathrm{X}_{4}-3.93 \times 10^{-3} \mathrm{X}_{3} \mathrm{X}_{4}-4.005 \times 10^{-5} \mathrm{X}_{1}^{2}$ $+1.434 \times 10^{-4} \mathrm{X}_{2}^{2}+0.036 \mathrm{X}_{3}^{2}-1.057 \times 10^{-3} \mathrm{X}_{4}^{2}$

Table 3 listed the analysis of variance (ANOVA) for the fitted quadratic polynomial model of extraction yields of galangin. A high model F-value $(F=28.10)$ and a low $p$-value $(p<0.0001)$, indicated that this model was highly significant. As showed in Table3, F-value and p-value of the lack of fit were 0.52 and 0.8155 , respectively,which implied it was not significant relative to the pure error and indicated that the model equation was adequate for predicting the yield of galangin under any combination of values of the variables. The higher the $\mathrm{R}^{2}$ Adj is, the better degree of correlation between the observed and predicted values ${ }^{[14]} \cdot \mathrm{R}^{2}{ }_{\text {Adj }}=0.9313$ in Table 3 implied that only less $7.0 \%$ of the total variations were not explained by model.A relatively low value of CV (1.57) in Table 3 showed a better precision and reliability of the experiments carried out. 
Table 3 Variance analysis of regression model

\begin{tabular}{llllll}
\hline Source & SS & DF & MS & F-value & Prob $>\mathrm{F}$ \\
\hline Model & 0.18 & 14 & 0.013 & 28.10 & $<0.0001$ \\
Residual & $6.269 \times 10^{-3}$ & 14 & $4.478 \times 10^{-4}$ & & \\
Lack of Fit & $3.55 \times 10^{-3}$ & 10 & $3.55 \times 10^{-4}$ & 0.52 & 0.8155 \\
Pure Error & $2.719 \times 10^{-3}$ & 4 & $6.798 \times 10^{-4}$ & & \\
Cor Total & 0.18 & 28 & & & \\
& $\mathrm{R}^{2}=0.9656$ & $\mathrm{R}_{\text {Adj }}^{2}=0.9313$ & $\mathrm{CV}=1.57$ & & \\
\hline
\end{tabular}

Table 4 showed the significant test results of regression coefficients, the results indicated that the independent variables $\mathrm{X}_{2}, \mathrm{X}_{4}$ and two quadratic terms $\mathrm{X}_{4}{ }^{2}$ significantly affected the yield of galangin $(\mathrm{P}<0.05)$, interaction term $\mathrm{X}_{1} \mathrm{X}_{2}, \mathrm{X}_{1} \mathrm{X}_{4}, \mathrm{X}_{2} \mathrm{X}_{3}, \mathrm{X}_{2} \mathrm{X}_{4}$ were significant,indicated there was a significant interaction between these variables.Meanwhile, the ratio of ethanol to raw material $\left(\mathrm{X}_{4}\right)$ was the major factor affecting the yield of galangin, then was the extraction temperature $\left(\mathrm{X}_{2}\right)$.

Table 4 Significance test of regression coefficient

\begin{tabular}{llllll}
\hline Variables & DF & SS & MS & F-value & P-value \\
\hline $\mathrm{X}_{1}$ & 1 & $6.855 \times 10^{-4}$ & $6.855 \times 10^{-4}$ & 1.53 & 0.2363 \\
$\mathrm{X}_{2}$ & 1 & 0.011 & 0.011 & 24.58 & 0.0002 \\
$\mathrm{X}_{3}$ & 1 & $1.222 \times 10^{-3}$ & $1.222 \times 10^{-3}$ & 2.73 & 0.1208 \\
$\mathrm{X}_{4}$ & 1 & 0.026 & 0.026 & 58.69 & $<0.0001$ \\
$\mathrm{X}_{1} \mathrm{X}_{2}$ & 1 & 0.011 & 0.011 & 23.48 & 0.0003 \\
$\mathrm{X}_{1} \mathrm{X}_{3}$ & 1 & $1.199 \times 10^{-4}$ & $1.199 \times 10^{-4}$ & 0.27 & 0.6129 \\
$\mathrm{X}_{1} \mathrm{X}_{4}$ & 1 & $2.772 \times 10^{-3}$ & $2.772 \times 10^{-3}$ & 6.19 & 0.0261 \\
$\mathrm{X}_{2} \mathrm{X}_{3}$ & 1 & 0.016 & 0.016 & 36.33 & $<0.0001$ \\
$\mathrm{X}_{2} \mathrm{X}_{4}$ & 1 & 0.097 & 0.097 & 217.38 & $<0.0001$ \\
$\mathrm{X}_{3} \mathrm{X}_{4}$ & 1 & $3.861 \times 10^{-4}$ & $3.861 \times 10^{-4}$ & 0.86 & 0.3688 \\
$\mathrm{X}_{1}{ }^{2}$ & 1 & $1.665 \times 10^{-3}$ & $1.665 \times 10^{-3}$ & 3.72 & 0.0744 \\
$\mathrm{X}_{2}{ }^{2}$ & 1 & $1.334 \times 10^{-3}$ & $1.334 \times 10^{-3}$ & 2.98 & 0.1063 \\
$\mathrm{X}_{3}{ }^{2}$ & 1 & $5.2 \times 10-4$ & $5.2 \times 10-4$ & 1.16 & 0.2994 \\
$\mathrm{X}_{4}{ }^{2}$ & 1 & $4.533 \times 10^{-3}$ & $4.533 \times 10^{-3}$ & 10.12 & 0.0067 \\
\hline $3.2 \mathrm{nalys}$ & & & & & \\
\hline
\end{tabular}

3.2 Analysis of Response Surface

Figs 1 to Figs 6 are tri-dimensional response surfaces and two-dimensional contour plots obtained from the multiple regression equation for yield of galangin,two variables were depicted in one tri-dimensional surface plots while the other variable kept at level zero. It is clear that the interaction relationships of extraction temperature $\left(\mathrm{X}_{2}\right)$ with the ethanol concentration $\left(\mathrm{X}_{1}\right)$, the rextraction time $\left(\mathrm{X}_{3}\right)$ and the ratio of ethanol to raw materia $\left(\mathrm{X}_{4}\right)$,also between the ethanol concentration $\left(\mathrm{X}_{1}\right)$ and the ratio of ethanol to raw materia on the yield $\left(\mathrm{X}_{4}\right)$ were significant,they were shown in Figs. 1, 3, 4 and 5,respectively, which indicated these three variables all had significant effect on the yield of galangin.

Fig. 1 is the response surface plot and contour plots of $X_{1}$ and $X_{2}$ and their interaction on the yield of galangin.As shown in the Fig,the curve in the figure shows gentle,the higher the ethanol concentration $\left(\mathrm{X}_{1}\right)$ and the extraction temperature $\left(\mathrm{X}_{2}\right)$ are ,the higher the yield of galangin is. The response surface in Fig. 2 is flat,which indicated that the interaction between the ethanol concentration and the extraction time is not significant.From Fig.3, it can be clear seen that, with the increase of ethanol concentration,the yield of galangin increase,so is the ratio of ethanol to materia, and the latter is more obvious..From Fig.4,we can see that when the temperature at a lower level,with the extension of the extraction time,the yield of galangin grows very fast;however,when the temperature is high, he yield decrease. When the extraction time is short,the yield of galangin increase with the increase of temperature,this trend becomes weaker with the temperature increasing.From Fig. 5 we can know that both the extraction temperature and the ratio of ethanol to materia have significant effect on the yield of galangin,so is their interaction,when the extraction time is short,the yield of galangin fall with the ratio of ethanol to materia increase,but with the extension of the extraction time,galangin yield increase rapidly at a higher liquid ratio.As can be seen from Figure 6, the interaction between the extraction time and the liquid ratio has little effect 
on the yield of galangin.
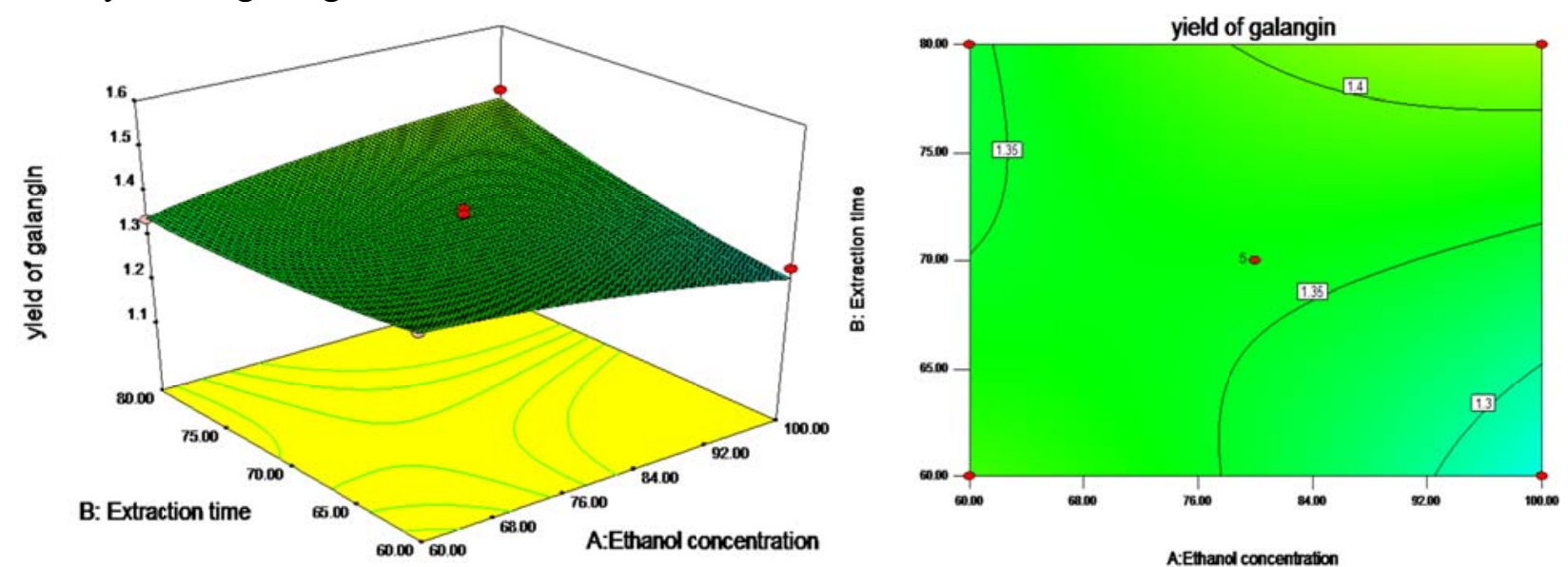

Fig.1. Response surface plot and contour plot of ethanol concentration and extraction temperaturel and their mutual interactions on the yield of galangin.
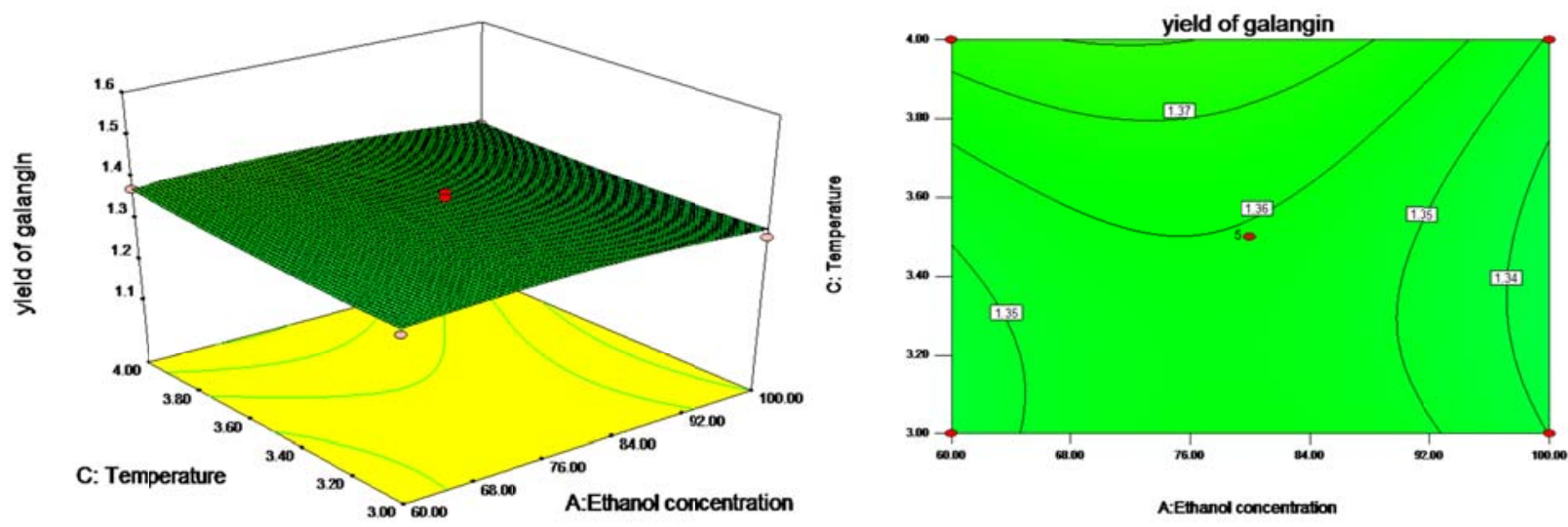

Fig.2. Response surface plot and contour plot of ethanol concentration and textraction time and their mutual interactions on the yield of galangin.
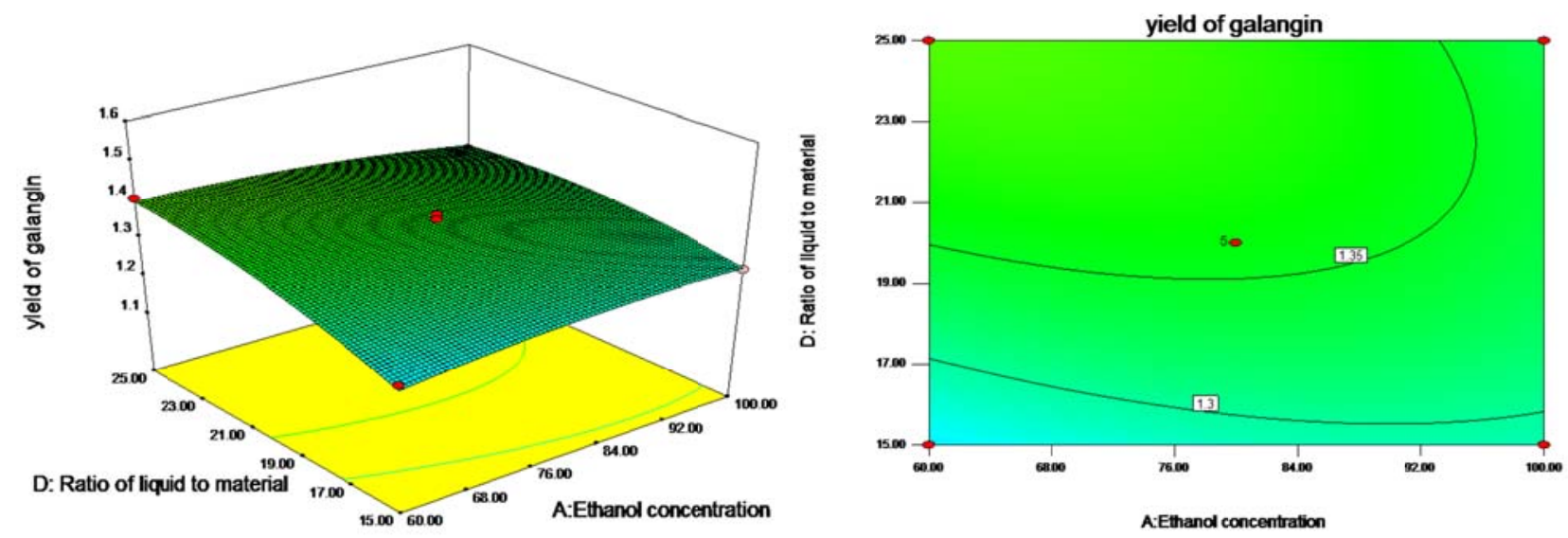

Fig.3. Response surface plot and contour plot of ethanol concentration and the ratio of ethanol to materia and their mutual interactions on the yield of galangin. 

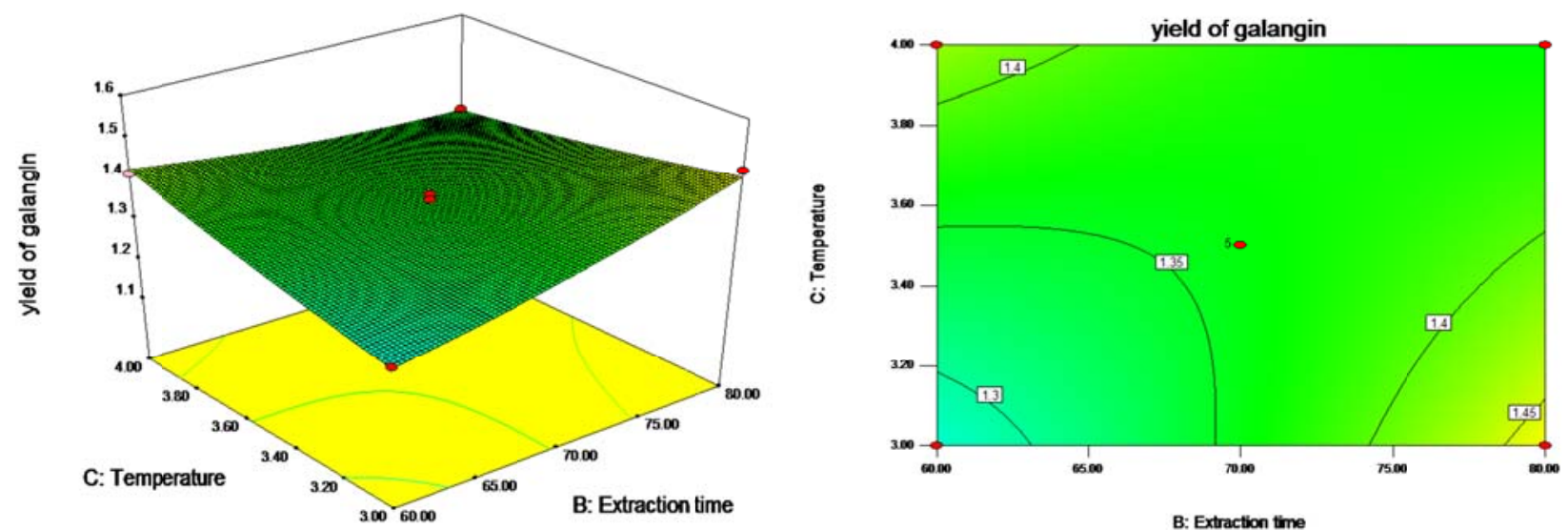

Fig.4. Response surface plot and contour plot of extraction temperature and textraction time and their mutual interactions on the yield of galangin.
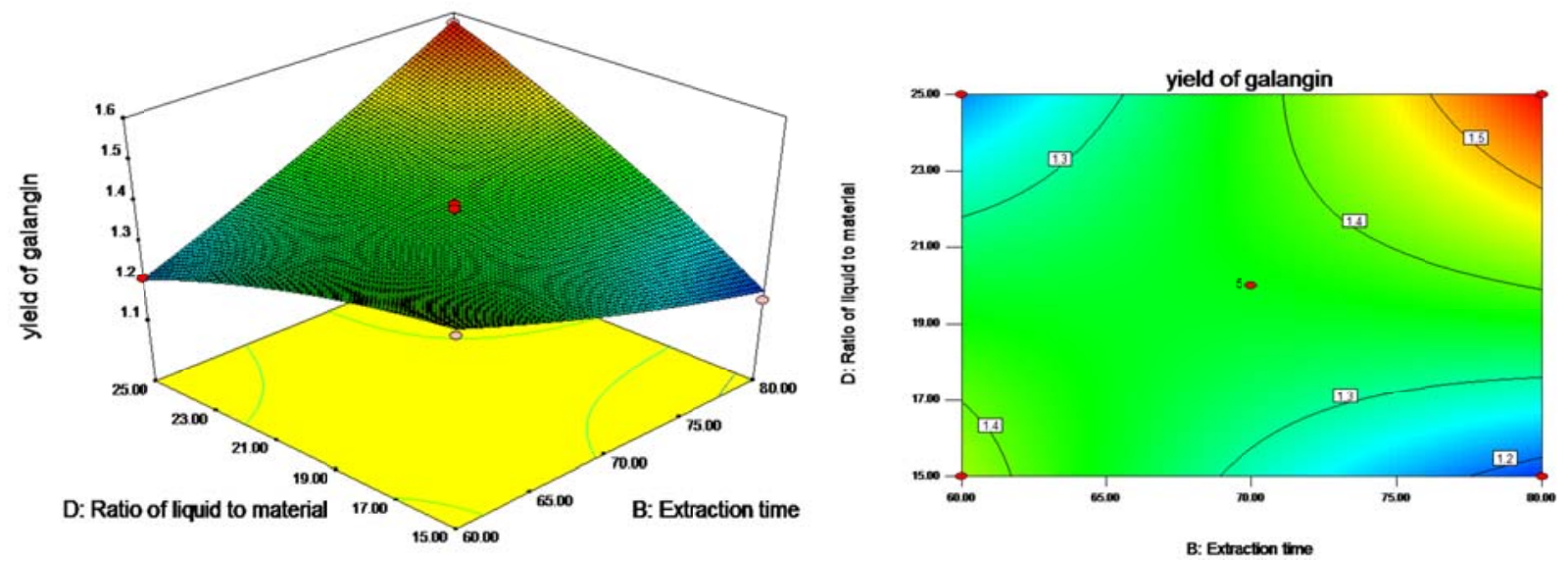

Fig.5. Response surface plot and contour plot of extraction temperature and the ratio of ethanol to materia and their mutual interactions on the yield of galangin.
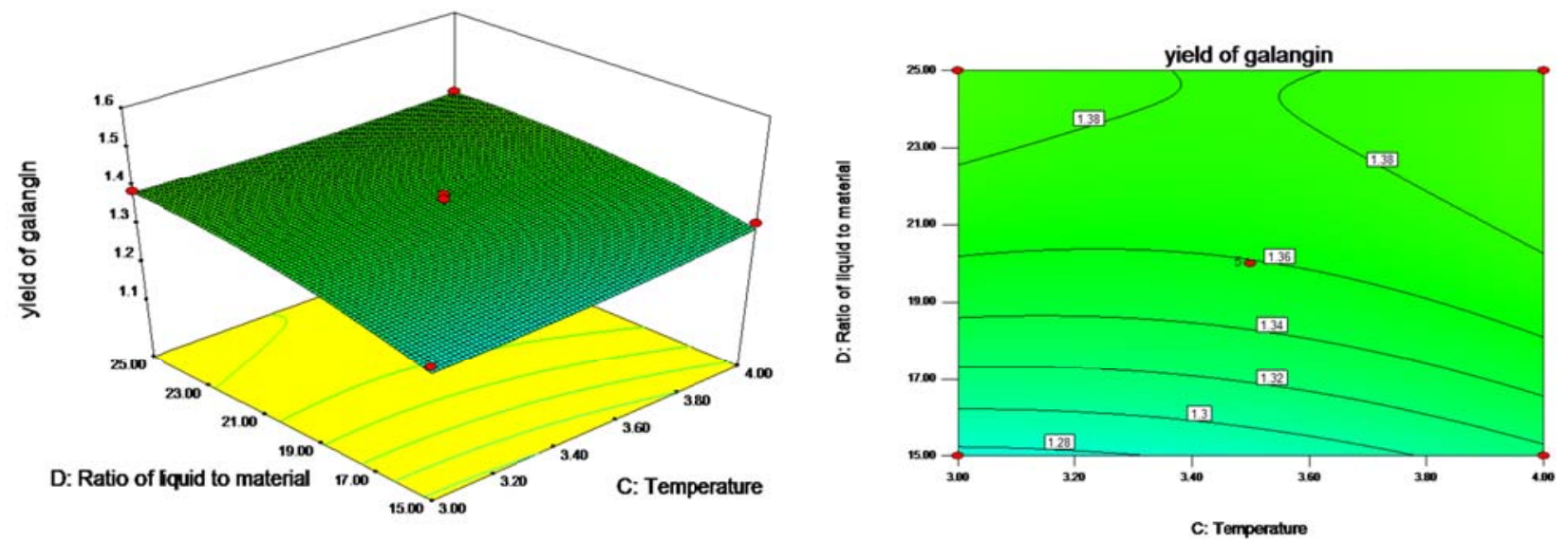

Fig.6. Response surface plot and contour plot of extraction temperature and the ratio of ethanol to materia and their mutual interactions on the yield of galangin.

\subsection{Optimization of Extracting Parameters and Validation of the Model}

The optimum response value predicted by the model equation was $1.66066 \%$, and the optimal conditions were the ethanol concentration of $93.9 \%$, the extraction temperature of $80{ }^{\circ} \mathrm{C}$, the extraction time of $3 \mathrm{~h}$, and the ratio of ethanol to materia $25 \mathrm{ml} \cdot \mathrm{g}^{-1}$. To test the reliability of results, experiment rechecking was performed using this modified optimal conditions:the ethanol concentration of $90 \%$, the extraction temperature of $80{ }^{\circ} \mathrm{C}$, the extraction time of $3 \mathrm{~h}$, and the ratio of ethanol to materia $25 \mathrm{ml} \cdot \mathrm{g}^{-1}$. Experiment was repeated 3 times, a mean value was $1.6543 \%$, it's close to the predicted value. The results of analysis confirmed that the response model was adequate ,and the extraction process parameters has practical value. 


\section{Conclusion}

Based on the single-factor experiments of galangin extraction from the galangal, Response surface methodology (RSM) was used to estimate and optimize the experimental variables, the ethanol concentration $(\%)$,extraction temperature $\left({ }^{\circ} \mathrm{C}\right)$, extraction time $(\mathrm{h})$, and ratio of ethanol to raw materia $\left(\mathrm{ml} \cdot \mathrm{g}^{-1}\right)$. The independent variables extraction temperature and liquid ratio had high significant effects on the response values, the interaction effects between extraction temperature and the ethanol concentration, the rextraction time, the ratio of ethanol to materia were significant,so are the ethanol concentration and the ratio of ethanol to raw materia.A high correlation of the quadratic polynomial mathematical model was gained and could be great employed to optimize galangin extraction from galangal.The optimal extraction conditions for the galangin were determined as follows:ethanol concentration $90 \%$, extraction temperature $80^{\circ} \mathrm{C}$, extraction time $3 \mathrm{~h}$, and the ratio of ethanol to materia $25 \mathrm{ml} \cdot \mathrm{g}^{-1}$. Under these conditions, the experimental yield of galangin was agreed closely with the predicted yield value.

\section{Acknowledgment}

This research was supported by the Promotion and Demonstration of Energy-saving and Qualityimproving Drying Technology in Tropical Place for Fruits and Vegetables, the Fundamental Scientific Research Funds for Chinese Academy of Tropical Agricultural Sciences (Galangal origin processing standardization research and demonstration) and the Guangdong Provincial Modern Agriculture (tropical agricultural products processing and detection) Industry Technology Research and Development Center.

\section{References}

[1] Chinese Pharmacopoeia Commission.Pharmacopoeia of People's Republic of China:2010 edition I Department[S].Beijing:Chinese Medical Science and Technology Press, 2010: 236.

[2] Hongfu Li, Yonghui Li,Yong Wang,et al.Advances in Studies on Chemical Constituents in Alpiniae Officinarum Rhizoma and their Pharmacological Activities.Chinese Journal of Experimental Traditional Medical Formulae.Vol. 20 (2014) No.7, p. 236-244.

[3] Wei Lv,Linghuo Jiang. Chemical Constituents and Pharmacological Activities of Apinia officinarum Hance.China Pharmaceuticals.Vol. 15 (2006) No.3, p.19-20.

[4] Qinghe Wu,Xianglu Rong,Ping Huang,et al.Pharmacodynamic Study of Galangin.Journal of Chinese Medicinal Materials. Vol. 23 (2000) No.11, p.699-700.

[5] Huizhen Huang,Dan Yang.Research on Development of the Chemical Composition and Pharmacological Activity of Alpinia Officinarum. Guangdong Chemical Industry.Vol. 36(2009) No.1, p.77-80.

[6] Yanfen Chen,Tao Jiang,Chunping Tang.Experimentai Study of Anti-inflammatory and Analgesic Effects of Total Flavonoids from Alpinia Officinarum Hance.Journal of Guangdong Pharmaceutical University.Vol. 25 (2009) No.2, p.188-191.

[7] Yanjun Yang,Congwei Sha,Xiaojuan Chen,et al.Study on the Analgesic Active Site of Alpinia Officinarum.Guangdong Medical Journal.Vol. 29 (2008)No.8,p.1286-1287.

[8] Shixia Huo,Xiaoming Peng,Li Gao,et al.Effects of Galangin with Different Purity on Melanin Synthesis and Related Gene Expression in Hunman Melanoman A375 Cells. Chinese Traditional and Herbal Drugs. Vol. 45 (2014) No.2, p.244-249.

[9] Shixia Huo,Yutong Kang,Xiaoming Peng,et al.Spectrum-effect Relasionship of Extract from Rhizome of Alpinia Officinarum on Promotion of Melanogenesis.Chinese Traditional and Herbal Drugs. Vol. 44 (2013) No.8, p.995-1002. 
[10] Heo M Y,Sohn S J,Au W W.Anti-genotoxicity of Galangin as a Cancer Chemopreventive Agent Candidate.Mutat Res.Vol. 488 (2001) No.2, p.135-150.

[11] Phang J M, Poore C M, Lopaczynska J,et al. Flavonol-stimulated Efflux of 7,12-dimethylbenz(a) Anthracene in Multidrug-resistant Breast Cancer Cells. Cancer Res.Vol. 53 (1993) No.24, p.5799-5981.

[12] Hui Luo,Chao Ma,Yajun Wang,et al.Study on Apoptosis of BEL-7402 Cells Induced by Galangin.Journal of Chinese Medicinal Materials.Vol. 31 (2008) No.8, p.1024-1027.

[13] Jun Wu,Min Wen,Haitao Zhang.Galangin Induces Apoptosis on Lung Cancer A549 Cells.Cancer Research on Prevention and Treatment.Vol. 38 (2011) No.11, p.1228-1231.

[14] Ravikumar K, Ramalingam S, Krishnan S,et al. Application of Response Surface Methodology to Optimize the Process Variables for Reactive Red and Acid Brown Dye Removal Using a Novel Absorbent. Dyes and Pigments.Vol. 15 (2006) No.70, p.18-26. 